\title{
Where to enhance rural palliative care? Developing a spatial model to identify suitable communities most in need of service enhancement
}

\author{
Nadine Schuurman ${ }^{1 *}$ (D) Michael E. Martin², Valorie A. Crooks ${ }^{1}$ and Ellen Randall ${ }^{3}$
}

\begin{abstract}
Background: In Canada, access to palliative care is a growing concern, particularly in rural communities. These communities have constrained health care services and accessing local palliative care can be challenging. The Site Suitability Model (SSM) was developed to identify rural "candidate" communities with need for palliative care services and existing health service capacity that could be enhanced to support a secondary palliative care hub. The purpose of this study was to test the feasibility of implementing the SSM in Ontario by generating a ranked summary of rural "candidate" communities as potential secondary palliative care hubs.

Methods: Using Census data combined with community-level data, the SSM was applied to assess the suitability of 12 communities as rural secondary palliative care hubs. Scores from 0 to 1 were generated for four equallyweighted components: (1) population as the total population living within a 1-h drive of a candidate community; (2) isolation as travel time from that community to the nearest community with palliative care services; (3) vulnerability as community need based on a palliative care index score; and (4) community readiness as five dimensions of fit between a candidate community and a secondary palliative care hub. Component scores were summed for the SSM score and adjusted to range from 0 to 1.

Results: Population scores for the 12 communities ranged widely (0.19-1.00), as did isolation scores (0.16-0.94). Vulnerability scores ranged more narrowly $(0.27-0.35)$, while community readiness scores ranged from 0.4-1.0. These component scores revealed information about each community's particular strengths and weaknesses. Final SSM scores ranged from a low of 0.33 to a high of 0.76 .

Conclusions: The SSM was readily implemented in Ontario. Final scores generated a ranked list based on the relative suitability of candidate communities to become secondary palliative care hubs. This list provides information for policy makers to make allocation decisions regarding rural palliative services. The calculation of each community's scores also generates information for local policy makers about how best to provide these services within their communities. The multi-factorial structure of the model enables decision makers to adapt the relative weights of its components.
\end{abstract}

Keywords: Spatial modelling, Palliative care services, Rural, Decision support

\footnotetext{
* Correspondence: nadine@sfu.ca

${ }^{1}$ Geography Department, Simon Fraser University, Robert C. Brown Hall, 8888 University Road, Burnaby, BC V5A 156, Canada

Full list of author information is available at the end of the article
}

(c) The Author(s). 2020 Open Access This article is licensed under a Creative Commons Attribution 4.0 International License, which permits use, sharing, adaptation, distribution and reproduction in any medium or format, as long as you give appropriate credit to the original author(s) and the source, provide a link to the Creative Commons licence, and indicate if changes were made. The images or other third party material in this article are included in the article's Creative Commons licence, unless indicated otherwise in a credit line to the material. If material is not included in the article's Creative Commons licence and your intended use is not permitted by statutory regulation or exceeds the permitted use, you will need to obtain permission directly from the copyright holder. To view a copy of this licence, visit http://creativecommons.org/licenses/by/4.0/ The Creative Commons Public Domain Dedication waiver (http://creativecommons.org/publicdomain/zero/1.0/) applies to the data made available in this article, unless otherwise stated in a credit line to the data. 


\section{Background}

Palliative care encompasses a range of services provided to support people "living with, or dying from, advanced illness" [1] in ways that optimize the quality of their life and, ultimately, their death $[1,2]$. Palliative care also extends beyond the patient, providing support to family members during end of life and bereavement; these family members, in turn, are often themselves key informal providers of palliative care [3]. Beyond family members, formal palliative services are delivered by a wide variety of providers including primary care physicians, specialist physicians, hospital staff, home care nurses, social workers, and spiritual advisors-with a goal of facilitating an end-of-life experience that is comfortable and dignified $[3,4]$.

Access to palliative care is a growing concern for Canada's aging population, where the number of Canadians over 65 years of age is projected to grow to almost one in four (23\%) by 2031 [5]. This growing population will necessitate adjustments in healthcare provision to ensure the range of and capacity for end-of-life services that are required to meet the needs of individuals during this life stage [6-9]. Canada, however, has lagged behind in preparing for its aging population and there are concerns about the gap between palliative care needs and available services [6,10-12]. While the increasing demand for palliative care is now beginning to receive greater attention in research literature, there remains an insufficient focus on the particular barriers to accessing this type of care in rural communities [13, 14].

Place of residence is recognized as a social determinant of health $[15,16]$. The mechanisms underwriting differences in health status between urban and rural residents are various (e.g., income, employment, socioeconomic status) and include access to health care services [15]. Globally, access to palliative care within one's home region is relatively limited in rural areas [17], and this holds true in Canada [18-20], where roughly 19\% of the population lives in areas designated as rural [21].

Across Canada, rural regions are characterized by geographic isolation, vast distances between communities, and relatively small populations. These factors contribute to challenges in the recruitment and retention of health care providers; in 2016, while 19\% of Canadians lived in rural communities, only $8 \%$ of physicians practiced in these communities [22]. For specialized palliative care, which ideally draws on a multi-disciplinary team of practitioners and specialists, the reality is even more stark: only $2.3 \%$ of Canada's specialists work in rural communities [22]. Palliative care in rural settings, therefore, is seldom provided by dedicated specialists [23]. Instead, rural patients rely on generalist providers and the limited formal and informal services available in their communities $[23,24]$. As palliative care increasingly moves beyond hospitals to be delivered at home, there is a need for strong community nursing capacity which is often not adequate in rural communities, and these nurses can be hindered by lack of sufficient support services and equipment [25]. These rural realities are troubling given the desire of many Canadians to die "in-place." Further, lack of adequate community-based care can impede the wishes of rural residents who want to die at home; in Western Canada, for example, rural residents have been found to spend more time in hospital in the last year of life compared to those living in urban centres [18].

\section{Spatial locational analysis modelling in support of improved access to rural palliative care}

Given the challenges with rural provision of palliative care services, there is a "need for innovative models of service provision" ([14], p., 256) in order to provide ready, local access to palliative care services in rural communities. In response, our research team has undertaken a multi-year research program that has resulted in the development of a spatial locational analysis model that supports the creation of secondary palliative care hubs (SPCHs) at regional levels [26-30]. Understanding the locational implications of health services as a dimension of access to adequate health care is recognized as a valuable input to decision making about siting health services [31-34], including palliative care [26]. An SPCH is a site that can enable access to local palliative care by combining existing health care provision with support from palliative care specialists in primary urban centres, through telemedicine and video-conferencing. The Site Suitability Model (SSM), which we introduce in this paper, enables the identification of rural communities with need for and community interest in palliative care services, as well as existing health service and personnel capacity, that have the potential to be enhanced to enable the creation of an SPCH [27, 28].

Working with a spatial sensibility, the SSM provides a locational analysis of rural communities with regard to their suitability as potential sites for an $\mathrm{SPCH}$.

The purpose of this study was to test the feasibility of implementing the newly refined SSM in order to identify and rank a set of rural communities in the province of Ontario based on their suitability as $\mathrm{SPCH}$ candidates. A secondary goal was to use the ranked suitability list as a form of evidence to allocate secondary palliative care hubs.

\section{Methods}

The assessment of a community's suitability as a candidate site for a rural SPCH rests a community's final SSM score. As a summative model, the SSM generates a total 
community score from four equally-weighted component scores.

\section{Components of the site suitability model Population}

Using readily available Canadian Census data, this component assesses need for local services and is operationalized as the total population living within a 1-h drive of a potential hub community. The working assumption is that the larger the catchment population, the larger the potential need for services. The choice of $1 \mathrm{~h}$ reflects considerations of barriers to patients' and providers' ability to reasonably travel during the end-of-life phase [27]. Travel-time catchments were generated with ArcGIS [35] using road data from the CanMap Network dataset [36] and Statistics Canada Census Blocks within each 1$\mathrm{h}$ catchment aggregated to provide population counts. The population component is scored as a range from 0 to 1 , based on the populations of the dissemination blocks within an hour drive time. The largest population is given a score on 1, and the remaining population centres are scored as a proportion relative to that centre.

\section{Isolation}

Using the ArcGIS "near facility" tool, travel times were estimated between SPCH candidate communities and the nearest community with palliative care services. This determinant of need assumes that the greater the travel time, the greater the need for access to local palliative care [27]. The isolation score is scored as a range from 0 to 1 . Communities that are a minimum of $4 \mathrm{~h}$ driving travel time from a community with existing specialized palliative care services are given a score of 1 . Communities whose travel time is less than $4 \mathrm{~h}$ are given proportional scores relative to the communities that scored 1 .

\section{Vulnerability}

The vulnerability component is a community's palliative care index (PCIX) score [30]. The PCIX incorporates four key variables associated with increased potential need for palliative care services, all drawn or generated from Statistics Canada data (Table 1).

Composite PCIX scores have a value between 0 and 1 : all four variables are evenly weighted and scored between 0 and 1, then summed and divided by 4 . Each PCIX element is scaled relative to the minimum and maximum values in each province; for example, the community (or communities) with the highest percentage of people over 75 is assigned a 1, and all other communities are scored relative to that community. More information on the PCIX scoring methodology is available in a paper by Schuurman et al. [30].

\section{Community readiness}

Community readiness is a measure of fit between an $\mathrm{SPCH}$ and a candidate community and introduces assessments of capacity. Operationalized as five binary Yes/No variables, it captures both community willingness and structural capacity (Table 2) [29]. Data for this component came from the Census as well as from information gathered through the review of relevant websites and by phone calls to relevant organizations.

As a summative score, in order to achieve an overall maximum score of 1 , each community readiness measure was assigned a value of 0.2 for a Yes.

\section{Site suitability model scoring}

The SSM generates community scores by totalling the four component scores-population, isolation, vulnerability, and community readiness. Each component score was equally weighted and summed yielding an initial model score ranging from 0 to 4 . Final values were scaled to $0-1$. A cut-point of 0.6 is suggested as a lower bound for eligibility, based on past experience; this value is discretionary and will need testing and possible adjustment in subsequent applications of the model.

\section{Community selection criteria}

For consideration in this study, the community selection process worked with the set of all population centres in Ontario, based on the 2011 Canadian Census [41]. We elected to implement the SSM at the provincial level because the provinces in Canada bear the primary responsibility for the provision of health care services. Ontario was selected because it is Canada's most populous province. The first step was to reduce this set to communities with over 5000 residents [42]. This constraint ensured that a new SPCH would service a sufficient catchment population. The set of population centres was then further reduced to only include those over a 1-h drive time to the nearest palliative care centre. The definition for a palliative care centre included general hospitals with more than 500 beds, identified from the Guide to Canadian Healthcare Facilities [43], as well as dedicated hospice facilities with more than three hospice beds, identified from government and community websites and verified over the telephone. This ensured we were identifying communities without easy spatial access to palliative care services.

\section{Results}

\section{Community selection}

The 2011 Canadian Census lists 270 population centres in Ontario; applying the criterion of a population of at least 5000 people reduced the set of possible population centres to 104 [44]. The set was further reduced by applying a 1-h drive time from the centroid of each 
Table 1 The elements of the PCIX, which is used as the vulnerability component for the SSM. See referenced papers for more detail on scoring $[30,37,38]$

\begin{tabular}{lll}
\hline Variable & Measure & Data sources \\
\hline Age & Percentage of catchment population over age 75 & $\begin{array}{c}\text { Statistics Canada } \\
\text { Census data }\end{array}$ \\
Sex & Percentage of catchment population that is female & Statistics Canada \\
& & Census data \\
Living & Percentage of catchment population that lives alone & Statistics Canada \\
arrangement & & Census data \\
VANDIX score & $\begin{array}{l}\text { Composite of 7 dissemination area-level indicators: percentage of residents who have not completed high } \\
\text { school; unemployment rate over age 15 years; percentage of lone-parent families; average total income; percent- }\end{array}$ & Statistics Canada \\
& age of homeowners; and employment ratio [37, 38] & \\
\hline
\end{tabular}

population centre to the closest palliative care centre; using the criterion of a drive greater than $1 \mathrm{~h}$ to such a centre produced a final list of 12 population centres across the province of Ontario (Fig. 1). These communities, for the most part, were found in the southern regions of the province.

\section{Component scores}

The population component scores for the 12 communities, indicating the size of local population an $\mathrm{SPCH}$ would serve, ranged widely from a low of 0.19 for the town of Perth to a high of 1.00 for Fort Frances. The isolation scores for these communities, signalling their relative distance from specialized palliative care services that were not available in their home communities, also ranged widely from a low of 0.16 for Hawkesbury to a high of 0.94 for Dryden.

Using the PCIX formula [30], overall vulnerability scores were generated from four sub-scores for these 12 Ontario communities. The vulnerability scores and ranged narrowly, from 0.27 to 0.35 (Table 3 ).

The community readiness scores for the Ontario communities are presented in Table 4. The municipality of Parry Sound is the only population centre to achieve the maximum score of 1 . The sub-scores reveal that community awareness is largely present across the set of communities, as are training and education resources. Telemedicine is being used in all communities and nearly all of the population centres had adequate access to physicians, with the exception of Haileybury. The momentum scores, however, show that formal initiatives towards local palliative services are largely lacking.

\section{Site suitability model scores}

Scores for the 12 communities (Table 5) ranged from a low of 0.33 for Hawkesebury to a high of 0.76 for Fort Frances, indicating the latter may be the most suitable location of this particular set of communities for further investigation and investment. Three communities had scores above the preliminary cut-point of 0.6 , designated as the proposed threshold for suitability. Having the component scores reveals where communities have weaknesses and strengths, and these can vary across site with the same score. For example, Kapuskasing and Kincardine have identical SSM scores, but their component scores reveal that while Kincardine had a fairly high community readiness score, Kapuskasing did not.

\section{Discussion}

The SSM represents a data-driven approach to identifying potential sites for SPCHs in rural areas that incorporates multiple factors that affect a community's need for

Table 2 The elements of the community readiness component for the SPCH SSM. See referenced papers for more detail on scoring

\begin{tabular}{|c|c|c|}
\hline Variable & Measure (Yes/No) & Data sources \\
\hline $\begin{array}{l}\text { Community } \\
\text { awareness }\end{array}$ & Presence of local hospice society & Community websites; BC Hospice Palliative Care Association listings \\
\hline $\begin{array}{l}\text { Telemedicine } \\
\text { utilization }\end{array}$ & Regular use of telemedicine ${ }^{a}$ & Confirmation from administrators at local hospitals of regular telemedicine use. \\
\hline $\begin{array}{l}\text { Adequate supply of } \\
\text { family doctors }\end{array}$ & $\begin{array}{l}\text { Family physician to population ratio: at } \\
\text { most } 1307 \text { persons per physician }\end{array}$ & $\begin{array}{l}\text { Number of family physicians: MDSelect database } \\
\text { Population: Statistics Canada Census data }\end{array}$ \\
\hline Momentum & Expression of interest for local hospice & $\begin{array}{l}\text { Confirmation from local hospice(s) of discussions or proposals for local hospice } \\
\text { residence }\end{array}$ \\
\hline
\end{tabular}

${ }^{a}$ For the purposes of this study, telemedicine is considered the provision of clinical support to local health care providers through use of information and communication technologies $[39,40]$ 


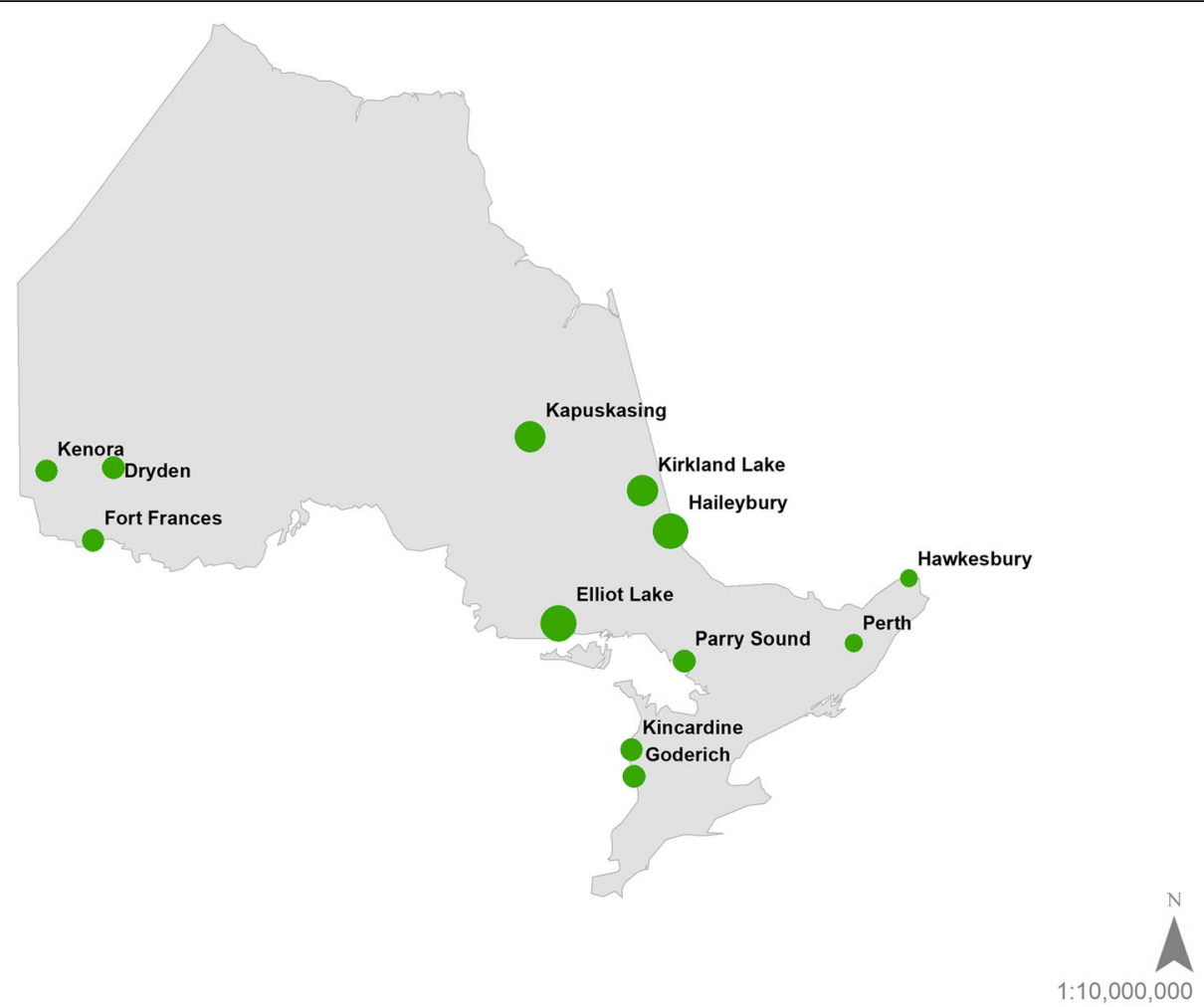

Fig. 1 Potential SPCH sites in Ontario. The 12 communities identified as potential SPCH sites in the province of Ontario. Dot size correlates to SPCH score. This map was created by the authors in ESRI ArcGIS

Table 3 Sub-scores and final vulnerability scores, based on the PCIX methodology, for potential SPCH host communities in

\begin{tabular}{|c|c|c|c|c|c|}
\hline \multicolumn{6}{|c|}{ Vulnerability (PCIX) Scores for possible Ontario SPCH sites } \\
\hline $\begin{array}{l}\text { Community } \\
\text { Name }\end{array}$ & $\begin{array}{l}\text { Age } \\
(\%)\end{array}$ & $\begin{array}{l}\text { Sex } \\
(\%)\end{array}$ & $\begin{array}{l}\text { Living } \\
\text { Arrangement } \\
(\%)\end{array}$ & VANDIX & VulnerabilityScore \\
\hline Dryden & 0.08 & 0.46 & 0.08 & 0.53 & 0.29 \\
\hline Elliot Lake & 0.13 & 0.46 & 0.12 & 0.67 & 0.35 \\
\hline Fort Frances & 0.10 & 0.46 & 0.10 & 0.52 & 0.30 \\
\hline Goderich & 0.11 & 0.49 & 0.09 & 0.47 & 0.29 \\
\hline Haileybury & 0.12 & 0.51 & 0.10 & 0.67 & 0.34 \\
\hline Hawkesbury & 0.09 & 0.50 & 0.08 & 0.48 & 0.28 \\
\hline Kapuskasing & 0.10 & 0.47 & 0.12 & 0.64 & 0.33 \\
\hline Kenora & 0.09 & 0.42 & 0.09 & 0.55 & 0.29 \\
\hline Kincardine & 0.12 & 0.50 & 0.10 & 0.49 & 0.30 \\
\hline $\begin{array}{l}\text { Kirkland } \\
\text { Lake }\end{array}$ & 0.10 & 0.46 & 0.10 & 0.63 & 0.32 \\
\hline Parry Sound & 0.18 & 0.47 & 0.10 & 0.52 & 0.30 \\
\hline Perth & 0.08 & 0.43 & 0.08 & 0.49 & 0.27 \\
\hline
\end{tabular}

and appropriateness as a potential SPCH hub. Developed and tested in the province of $\mathrm{BC}$, the latest model was tested in the province of Ontario, demonstrating its portability and utility in any context where there are readily accessible Census, spatial, and local resource data to generate the component and final SSM scores. The model, therefore, enhances the ability of provincial health care decision makers to utilize these types of publicly available data to generate assessments of rural communities' suitability as potential SPCH sites which can provide much needed local end-of-life resources for aging ex-urban populations in Canada and beyond. Though designed and tested in individual provinces in Canada, this model has transferability to other contexts that face similar challenges in rural health service provision, such as Australia and the United States.

The results detailed for the Ontario communities reveal the architecture of the SSM. Constructed using a set of key information-rich components, the model returns a corresponding set of component sub-scores that extend the model's value. Each component on its own provides valuable information for health care decision makers about key aspects of the populations they are trying to serve. This is particularly apparent in a component like community readiness, which provides stakeholders with key information about a community's 
Table 4 Community Readiness scores for potential SPCH host communities in Ontario

\begin{tabular}{|c|c|c|c|c|c|c|}
\hline \multicolumn{7}{|c|}{ Community Readiness Scores for possible Ontario SPCH sites } \\
\hline Community Name & Community awareness & Training/education & Telemedicine & Adequate supply of FPs & Momentum & Score \\
\hline Dryden & 0.2 & 0.2 & 0.2 & 0.2 & 0 & 0.8 \\
\hline Elliot Lake & 0.2 & 0 & 0.2 & 0.2 & 0 & 0.6 \\
\hline Fort Frances & 0.2 & 0.2 & 0.2 & 0.2 & 0 & 0.8 \\
\hline Goderich & 0.2 & 0 & 0.2 & 0.2 & 0 & 0.6 \\
\hline Haileybury & 0.2 & 0.2 & 0.2 & 0 & 0 & 0.6 \\
\hline Hawkesbury & 0 & 0.2 & 0.2 & 0.2 & 0 & 0.6 \\
\hline Kapuskasing & 0 & 0 & 0.2 & 0.2 & 0 & 0.4 \\
\hline Kenora & 0.2 & 0.2 & 0.2 & 0.2 & 0 & 0.8 \\
\hline Kincardine & 0.2 & 0.2 & 0.2 & 0.2 & 0 & 0.8 \\
\hline Kirkland Lake & 0.2 & 0.2 & 0.2 & 0.2 & 0 & 0.8 \\
\hline Parry Sound & 0.2 & 0.2 & 0.2 & 0.2 & 0.2 & 1.0 \\
\hline Perth & 0.2 & 0.2 & 0.2 & 0.2 & 0 & 0.8 \\
\hline
\end{tabular}

relative strengths and weaknesses in this domain. Kelly et al. [24], for example, identified insufficient community-level understanding of palliative care as a potential challenge to overcome in the development of local rural palliative services. The community readiness component has indicators that speak directly to this need for local understanding-e.g., the community awareness indicator-and can aid decision makers in pinpointing particular vulnerabilities within their communities that need prioritizing.

Further, the model is inherently flexible. Components can be modified, dropped, or added according to sitespecific priorities. Similarly, weights can be valued and revalued based on evolving resources and population needs. For example, in the Atlantic province of Newfoundland \& Labrador the factor of drive time might benefit from being adjusted or weighted differently in acknowledgement of the impact of the coastal environment on the road network [45]. This adaptability facilitates a critical input to ensuring successful implementation of the tool at the provincial or local level, and ultimately, the validation of its outputnamely, the expert knowledge of local stakeholders. These decision makers can draw on their experience and expertise to recalibrate the SSM to best represent the current reality within their communities.

Given the importance of "on-the-ground" knowledge and expertise to the optimal calibration of the SSM,

Table 5 Summary of the SSM component scores and final SPCH SSM scores. Component scores are summed and divided by four to generate the final scores

\begin{tabular}{llllll}
\hline SSM Scores for possible Ontario SPCH sites & & & & \\
\hline Community Name & Population Score & Isolation Score & VulnerabilityScore & Community Readiness Score & SSM Score \\
\hline Dryden & 0.81 & 0.94 & 0.29 & 0.80 & 0.71 \\
Elliot Lake & 0.68 & 0.45 & 0.35 & 0.60 & 0.52 \\
Fort Frances & 1.00 & 0.93 & 0.30 & 0.60 & 0.76 \\
Goderich & 0.23 & 0.22 & 0.29 & 0.60 & 0.34 \\
Haileybury & 0.56 & 0.41 & 0.34 & 0.60 & 0.48 \\
Hawkesbury & 0.26 & 0.16 & 0.28 & 0.40 & 0.33 \\
Kapuskasing & 0.46 & 0.44 & 0.33 & 0.80 & 0.41 \\
Kenora & 0.87 & 0.56 & 0.29 & 0.80 & 0.63 \\
Kincardine & 0.25 & 0.27 & 0.30 & 0.80 & 0.41 \\
Kirkland Lake & 0.26 & 0.26 & 0.32 & 1.00 & 0.41 \\
Parry Sound & 0.21 & 0.25 & 0.30 & 0.80 & 0.44 \\
Perth & 0.19 & 0.22 & 0.27 & \\
\hline
\end{tabular}


future research with this model is intended in order to explore the "fit" between SSM community scores and community stakeholders' perceptions of their communities' actual suitability and viability for becoming an $\mathrm{SPCH}$. A series of case studies comprising interviews with key stakeholders is envisioned.

\section{Limitations and considerations}

One of the key strengths of the SSM, the ability to adjust weights to reflect individual local contexts, is also a potential shortcoming in that the model does not offer a "one-size-fits-all" weighting system that is sure to be appropriate across all communities. Deployment of the tool at a provincial level across multiple communities, for example, will require input from community-level stakeholders who will need to bring their expert knowledge to bear on assigning appropriate weights to the model's components. The SSM may also not always account for particular contextual factors that could influence the delivery of palliative care within individual rural communities, for instance a factor such as health system bureaucracy [24]. Interpreting the community scores within the context of a larger structural influences such as the health system will again depend on the expertise of the decision makers tasked with making decisions about allocating palliative care resources.

\section{Conclusions}

The SSM is the product of over a decade of iterative development to create a nuanced and flexible model that can draw upon available public data and readily collected local data to generate information that will aid decision makers at community and provincial levels to identify a community's suitability as an SPCH site. The model is information-rich: given its multi-factorial structure, even if communities are not ultimately selected as $\mathrm{SPCH}$ sites, the calculation of their population, isolation, vulnerability, and community readiness component scores provides policy makers and other stakeholders with key information that can inform decisions about resource allocation. Given the multi-factorial structure of the model, the SSM will enable decision makers to adapt the relative weights of its components to generate scores that reflect their individual knowledge about the needs and resources of their jurisdictions.

\section{Abbreviations}

BC: British Columbia; PCIX: Palliative Care Index; SPCH: Secondary Palliative Care Hub; SSM: Site Suitability Model

\section{Acknowledgements}

Not applicable.

\section{Authors' contributions}

NS helped conceptualize the model, was involved in all stages of its development and analysis, and participated in reviewing and revising the manuscript. MM undertook all the GIS analyses for this study and drafted the original manuscript. VAC helped conceptualize and develop the model, and participated in reviewing and revising the manuscript. ER participated in the conceptualization of the manuscript and undertook manuscript revising and editing. The authors read and approved the final manuscript.

\section{Funding}

This study was funded by an Operating Grant awarded by the Canadian Institutes of Health Research (CIHR). The funding did not affect the design of the study, data collection, analysis or interpretation. VAC holds the Canada Research Chair in Health Service Geographies and a Scholar Award from the Michael Smith Foundation for Health Research. Her research time is protected through both awards.

\section{Availability of data and materials}

1) Statistics Canada Census of the Population, and GIS Data, as facilitated through the University of Toronto CHASS Database:

StatsCan Data: https://www150.statcan.gc.ca/n1/en/type/data?MM=1

CHASS: http://datacentre.chass.utoronto.ca/. This is a closed dataset, open only to Canadian University researchers.

2) DMTI CanMap Route Logistics network Datasets:

https://www.dmtispatial.com/canmap/. This is a closed dataset, open only to

Canadian University researchers.

3) AUCC lists of Canadian university and colleges:

https://www.aucc.ca/. This is an open dataset.

4) Scott's Directories MD Select Canadian Medical Directory:

https://www.mdselect.ca/canadian-doctors-directory/. This dataset is available to purchase.

5) Community hospice societies:

This data was gathered from individual community websites, direct calls to hospitals and practitioners as well as direct calls to Telehealth Ontario.

https://www.ontario.ca/page/get-medical-advice-telehealth-ontario . These data are freely $a$.

\section{Ethics approval and consent to participate}

Ethics Approval was waived by Simon Fraser University Office of Research Ethics based on the nature of the analysis and absence of human subjects.

Consent for publication

Not applicable.

\section{Competing interests}

The authors declare that they have no competing interests.

\section{Author details}

${ }^{1}$ Geography Department, Simon Fraser University, Robert C. Brown Hall, 8888 University Road, Burnaby, BC V5A 1S6, Canada. ${ }^{2}$ University of Auckland, 23 Symonds Street, Auckland 1142, New Zealand. ${ }^{3}$ School of Population and Public Health, University of British Columbia, 2206 East Mall, Vancouver, BC V6T 1Z3, Canada.

Received: 4 June 2019 Accepted: 24 February 2020

Published online: 04 March 2020

\section{References}

1. Canadian Hospice Palliative Care Association. What is palliative care? http:// www.chpca.net/family-caregivers/faqs.aspx. Accessed 23 February 2018.

2. World Health Organization. WHO Definition of Palliative Care. http://www. who.int/cancer/palliative/definition/en/. Accessed 21 Feb 2018.

3. Canadian Hospice Palliative Care Association. Who provides palliative care? http://www.chpca.net/family-caregivers/faqs.aspx. Accessed 21 Feb 2018.

4. National Consensus Project for Quality Palliative Care. Clinical Practice Guidelines for Quality Palliative Care. 3rd ed. Pittsburgh; 2013.

5. Statistics Canada. Age and sex, and type of dwelling data: Key results from the 2016 Census. https://www150.statcan.gc.ca/n1/daily-quotidien/170503/ dq170503a-eng.htm? HPA=1. Accessed 1 Nov 2018.

6. Canadian Hospice Palliative Care Association. The pan-Canadian gold standard for palliative home care-towards equitable access to high quality hospice palliative and end-of-life Care at Home. Ottawa: Canadian Hospice Palliative Care Association; 2006.

7. Connor SR. Development of hospice and palliative care in the United States. OMEGA. 2008:56:89-99. 
8. Krakauer EL. Just palliative care: responding responsibly to the suffering of the poor. J Pain Symptom Manag. 2008;36:505-12.

9. Kuebler KK, Lynn J, Von Rohen J. Perspectives in palliative care. Semin Oncol Nurs. 2005:21:2-10.

10. Carstairs S. Still not there: quality end-of-life care: a progress report; 2005.

11. Romanow RJ. Shape the future of health care: interim report. Saskatoon: Commission on the Future of Health Care in Canada; 2002.

12. Standing Senate Committee on Social Affairs Science and Technology. Quality end-of-life care: The right of every Canadian. Final report. https:// sencanada.ca/content/sen/committee/362/upda/rep/repfinjun00-e.htm. Accessed 3 Mar 2018.

13. Crooks VA, Schuurman N. Reminder: palliative care is a rural medicine issue. Can J Rural Med. 2008;13:139-41.

14. Robinson CA, Pesut B, Bottorff JL, Mowry A, Broughton S, Fyles G. Rural palliative care: A comprehensive review. J Palliat Med. 2009;12:253-8.

15. Canadian Institute for Health Information \& Canadian Population Health Initiative. How healthy are rural Canadians? An assessment of their health status and health determinants. Ottawa: Canadian Institute for Health Information; 2006

16. Kelly MP, Morgan A, Bonnefoy J, Butt J, Bergman V. The social determinants of health: Developing an evidence base for political action. Final Report to World Health Organization Commission on the Social Determinants of Health. http://cdrwww.who.int/social_determinants/resources/mekn_final_ report_102007.pdf; 2007.

17. Evans R, Stone D, Elwyn G. Organizing palliative care for rural populations: a systematic review of the evidence. Fam Pract. 2003;20:304-10

18. Canadian Institute for Health Information. Health care use at the end of life in Western Canada. Ottawa: $\mathrm{ClHI} ; 2007$.

19. Collier R. Access to palliative care varies widely across Canada. CMAJ. 2011;183:E87-8.

20. Bacon J. Hospice palliative home care in Canada: A progress report. Ottawa: Quality End-of-Life Care Coalition of Canada (QECCC); 2008

21. Statistics Canada. Population counts, for Canada, provinces and territories, census divisions, population centre size groups and rural areas, 2016 Census 100\% data. http://www12.statcan.gc.ca/census-recensement/2016/dp-pd/hltfst/pd-pl/Table.cfm? Lang=Eng\&T=703\&S=87\&O=A. Accessed 12 Mar 2018.

22. Canadian Institute for Health Information. Supply, distribution and migration of physicians in Canada, 2016: Data Tables. Ottawa: Canadian Institute for Health Information. https://secure.cihi.ca/estore/productSeries.htm?pc= PCC34; 2017.

23. Kelley ML. Developing rural communities' capacity for palliative care: a conceptual model. J Palliat Care. 2007;23:143-53.

24. Kelley ML, Williams A, DeMiglio L, Mettam H. Developing rural palliative care: validating a conceptual model. Rural Remote Health. 2011;11:1717.

25. Kaasalainen S, Brazil K, Williams A, Wilson D, Willison K, Marshall D, Taniguchi A. Barriers and enablers to providing palliative care in rural communities: a nursing perspective. J Rural Community Dev. 2012;7:4-19.

26. Cinnamon J, Schuurman N, Crooks VA. A method to determine spatial access to specialized palliative care services using GIS. BMC Health Serv Res. 2008;8:140.

27. Cinnamon J, Schuurman N, Crooks VA. Assessing the suitability of host communities for secondary palliative care hubs: a location analysis model. Health Place. 2009;15:822-30

28. Crooks VA, Castleden H, Schuurman N, Hanlon N. Visioning for secondary palliative care service hubs in rural communities: a qualitative case study from British Columbia's interior. BMC Palliative Care. 2009:8:15.

29. Crooks VA, Schuurman N, Cinnamon J, Castleden H, Johnston R. Refining a location analysis model using a mixed methods approach: community readiness as a key factor in siting rural palliative care services. J Mixed Methods Res. 2011;5:77-95.

30. Schuurman N, Martin M, Crooks VA, Randall E. The development of a spatial palliative care index instrument for assessing population-level need for palliative care services. Health Place. 2018;49:50-8.

31. Mahar S, Bretthauer KM, Salzarulo PA. Locating specialized service capacity in a multi-hospital network. Eur J Oper Res. 2011;212:596-605.

32. Rahman S, Smith DK. Use of location-allocation models in health service development planning in developing nations. Eur J Oper Res. 2000;123:437-52.

33. Syam SS, Côté MJ. A location-allocation model for service providers with application to not-for-profit health care organizations. Omega. 2010;38:157-66.

34. Shah T, Bell S, Wilson K. Spatial accessibility to health care services: identifying under-serviced neighbourhoods in Canadian urban areas. PLoS One. 2016;11:e0168208.
35. Schuurman N, Fiedler RS, Grzybowski SCW, Grund D. Defining rational hospital catchments for non-urban areas based on travel-time. Int J Health Geogr. 2006;5:1-11.

36. DMTI Spatial. CanMap Route Logistics Network Dataset v2011.3. 2011.

37. Bell N, Hayes MV. The Vancouver area Neighbourhood deprivation index (VANDIX): a census-based tool for assessing small-area variations in health status. Can J Public Health. 2012;103:S28-32.

38. Bell N, Schuurman N, Oliver L, Hayes MV. Towards the construction of placespecific measures of deprivation: a case study from the Vancouver metropolitan area. Can Geogr. 2007;51:444-61.

39. Wootton R, Menzies J, Ferguson P. Follow-up data for patients managed by store and forward telemedicine in developing countries. J Telemed Telecare. 2009;15:83-8.

40. World Health Organization. Telemedicine. Opportunities and development in Member States. In: Global Observatory for eHealth. Geneva: World Health Organization; 2010.

41. Statistics Canada. 2011 census of the population. Ottawa: Statistics Canada; 2011.

42. Statistics Canada. 2006 census of the population. Ottawa: Statistics Canada; 2006.

43. Canadian Health Association. HealthCareCAN | Guide to Canadian Healthcare Facilities. 2012

44. Ontario Ministry of Health and Long-term Care. Ontario Health Insurance Plan - Out of Province Services (OOP)- Prior Approval. http://www.health. gov.on.ca/en/public/programs/ohip/outofprovince/priorapproval.aspx. Accessed 11 Nov 2018.

45. Schuurman N, Amram O, Crooks VA, Johnston R, Williams A. A comparative analysis of potential spatio-temporal access to palliative care services in two Canadian provinces. BMC Health Serv Res. 2015;15:270.

\section{Publisher's Note}

Springer Nature remains neutral with regard to jurisdictional claims in published maps and institutional affiliations.

Ready to submit your research? Choose BMC and benefit from:

- fast, convenient online submission

- thorough peer review by experienced researchers in your field

- rapid publication on acceptance

- support for research data, including large and complex data types

- gold Open Access which fosters wider collaboration and increased citations

- maximum visibility for your research: over $100 \mathrm{M}$ website views per year

At $\mathrm{BMC}$, research is always in progress.

Learn more biomedcentral.com/submissions 